\title{
Anti-termitic activities of essential oils from coniferous trees against Coptotermes formosanus
}

\author{
Sen-Sung Cheng, Hui-Ting Chang, Chi-Lin Wu, Shang-Tzen Chang * \\ School of Forestry and Resource Conservation, National Taiwan University, Taipei 106, Taiwan
}

Received 20 October 2005; received in revised form 3 January 2006; accepted 4 January 2006

Available online 21 February 2006

\begin{abstract}
In this study, the anti-termitic activities of 11 essential oils from three species of coniferous tree against Coptotermes formosanus Shiraki were investigated using direct contact application. Results demonstrated that at the dosage of $10 \mathrm{mg} / \mathrm{g}$, the heartwood and sapwood essential oils of Calocedrus macrolepis var. formosana and Cryptomeria japonica and the leaf essential oil of Chamaecyparis obtusa var. formosana had 100\% mortality after $5 \mathrm{~d}$ of test. Among the tested essential oils, the heartwood essential oil of C. macrolepis var. formosana killed all termites after $1 \mathrm{~d}$ of test, with an $\mathrm{LC}_{50}$ value of $2.6 \mathrm{mg} / \mathrm{g}$, exhibiting the strongest termiticidal property. The termiticidal effect of heartwood essential oil was due to its toxicity and its repellent action.
\end{abstract}

(C) 2006 Elsevier Ltd. All rights reserved.

Keywords: Calocedrus macrolepis var. formosana; Cryptomeria japonica; Chamaecyparis obtusa var. formosana; Heartwood; Essential oil; Coptotermes formosanus; Anti-termitic activity

\section{Introduction}

Biodegradation of wood caused by termites is recognized as one of the most serious problems for wood utilization. It is also known that termites damage a variety of materials ranging from paper fabrics to even non-cellulosic materials such as asbestos, asphalt bitumen, lead, and metal foils (Bultman et al., 1979). Damage to wooden structures and other cellulosic materials by termites has been estimated to exceed $\$ 3$ billion annually worldwide ( $\mathrm{Su}$ and Scheffrahn, 1990). Coptotermes formosanus Shiraki is the termite species responsible for most wood destruction in countries such as Taiwan, Japan, and parts of the United States (Chang and Cheng, 2002).

It is also well known that extractives have a significant effect on the durability of wood (Chang et al., 1999), and

\footnotetext{
* Corresponding author. Tel.: +88623366 4626; fax: +886223654520.

E-mail address: peter@ntu.edu.tw (S.-T. Chang).
}

certain extractives from wood tissues can provide protection against harmful insects. For nondurable woods, it may be necessary to use inorganic compounds or synthetic pesticides to preserve the woods and prolong their application life. To avoid environmental pollution and health problems caused by the use of traditional wood preservatives or synthetic pesticides, there is increasing interest in naturally occurring toxicants from plants (Chang et al., 2001). Many plant extracts and essential oils (Arihara et al., 2004; Chang et al., 2001; Chang and Cheng, 2002; Cheng et al., 2004; Park and Shin, 2005; Sakasegawa et al., 2003; Sogabe et al., 2000) may be the alternative sources of termite control agents because they constitute rich sources of bioactive chemicals. Therefore, the purpose of this study is to determine the bioactivity of 11 essential oils from three coniferous trees against $C$. formosanus Shiraki. In addition, the related anti-termitic functions of Calocedrus macrolepis var. formosana heartwood and sapwood essential oils were also examined. 


\section{Methods}

\subsection{Plant materials}

Heartwood, bark and leaf of Chamaecyparis obtusa var. formosana were collected from the Dasi working circle located in Ilan. Heartwood, sapwood, bark and leaf of both Cryptomeria japonica and C. macrolepis var. formosana were collected from the Experimental Forest of National Taiwan University. The species were identified and voucher specimens (COHO01, COBO01, COLO01, CJHO01, CJSO01, CJBO01, CJLO01, CFHO01, CFSO01, CFBO01 and CFLO01) were deposited in the laboratory of wood chemistry (School of Forestry and Resource Conservation, National Taiwan University).

\subsection{Essential oil distillation}

The samples ( $200 \mathrm{~g}$ each), in triplicate, were subjected to hydrodistillation in a Clevenger-type apparatus for $6 \mathrm{~h}$ and the contents of the essential oils were determined (Chang et al., 2001). Eleven essential oils were stored in airtight containers prior to anti-termitic tests.

\subsection{Termite}

The test termite species, $C$. formosanus Shiraki, was collected from Taipei in Northern Taiwan. The colony was reared in an incubator at $26.5^{\circ} \mathrm{C}$ and $80 \%$ relative humidity $(\mathrm{RH})$ for more than one year. Water and newspaper were used as the food source.

\subsection{Anti-termitic activity}

The no-choice bioassay method of Kang et al. (1990) was employed to evaluate the anti-termitic activity of the 11 essential oils. Samples of 1, 2.5, 5 and $10 \mathrm{mg}$ of the essential oils dissolved in $600 \mu \mathrm{l}$ of ethanol were applied to $1 \mathrm{~g}$ filter paper samples (Whatman No. $3,8.5 \mathrm{~cm}$ in diameter). A piece of filter paper treated with solvent only was used as a control. After the solvent was removed from the treated filter papers by air-drying at ambient temperature, 33 active termites (30 workers and 3 soldiers) above the third instar were put on each piece of filter paper in a Petri dish $(9 \mathrm{~cm}$ in diameter $\times 1.5 \mathrm{~cm}$ in height). The dishes with covers were then placed in an incubator at $26.5^{\circ} \mathrm{C}$ and $80 \% \mathrm{RH}$. A few drops of water were periodically dripped onto the bottom edge of each Petri dish. Three replicates were made for each test sample, and the mortality of the termites was counted daily for $14 \mathrm{~d}$.

\subsection{Anti-termitic function of essential oil}

The method of Ohtani et al. (1996) was employed to distinguish the termiticidal, repellent and respiratory poisoning functions of essential oils. For testing method A, filter paper was impregnated with essential oils and distilled water. For testing method B, one half of the filter paper was impregnated with essential oils and distilled water and the other half of the filter paper was impregnated with distilled water. For testing method $\mathrm{C}$, essential oils were applied into $2.5 \mathrm{~cm}$ Petri dish and filter paper was impregnated with distilled water. The procedures used were the same as those described in Section 2.4.

\subsection{Statistical analysis}

The Scheffe multiple comparison procedure from the SAS statistical program was employed to evaluate differences in percent mortality for the anti-termitic tests. Results with $P<0.05$ were considered statistically significant. All results were obtained from three independent experiments and expressed as mean $\pm \mathrm{SD}$.

\section{Results and discussion}

\subsection{Essential oil yields by water distillation}

The 11 essential oils were distilled from various parts of three coniferous tree species, and analysis indicated that the yields of essential oils ranged from 0.2 to $27.4 \mathrm{ml} / \mathrm{kg}$. The yields of heartwood, bark and leaf essential oils of $C$. obtusa var. formosana were $9.5,2.6$ and $14.1 \mathrm{ml} / \mathrm{kg}$, respectively. The yields of heartwood, sapwood, bark and leaf essential oils of $C$. japonica and C. macrolepis var. formosana were $3.8,1.3,6.3$ and $27.4 \mathrm{ml} / \mathrm{kg}$ and $5.8,0.2,5.5$ and $3.4 \mathrm{ml} / \mathrm{kg}$, respectively.

\subsection{Anti-termitic activities of essential oils}

As can be seen from Table 1, three of the 11 essential oils extracted from the three coniferous tree species were incapable of killing all termites at a dosage of $10 \mathrm{mg} / \mathrm{g}$ after $14 \mathrm{~d}$. Thus, the essential oils of bark of $C$. japonica, and bark and leaf of C. macrolepis var. formosana were considered inactive. Eight essential oils showed toxicity against $C$. formosanus: heartwood, bark and leaf essential oils of C. obtusa var. formosana; heartwood and sapwood essential oils of $C$. macrolepis var. formosana; and heartwood, sapwood and leaf essential oils of $C$. japonica. The leaf essential oil of $C$. japonica as well as heartwood and bark essential oils of $C$. obtusa var. formosana killed all termites within $12 \mathrm{~d}, 10 \mathrm{~d}$ and $14 \mathrm{~d}$, respectively; the heartwood and sapwood essential oils of C. macrolepis var. formosana and C. japonica and the leaf essential oil of $C$. obtusa var. formosana showed $100 \%$ mortality after $5 \mathrm{~d}$ of test. Among the eight essential oils, heartwood essential oil of C. macrolepis var. formosana killed all termites after $1 \mathrm{~d}$ of test, indicating that it had the strongest toxicity against $C$. formosanus. In our previous studies, the termite mortalities of heartwood and sapwood essential oils of Taiwania cryptomerioides were $56 \%$ and $32 \%$ at a dosage of $10 \mathrm{mg} / \mathrm{g}$ after $14 \mathrm{~d}$ (Chang et al., 2001). 
Table 1

Anti-termitic activities of 11 essential oils extracted from three coniferous trees against $C$. formosanus at a dosage of $10 \mathrm{mg} / \mathrm{g}$

\begin{tabular}{lccc}
\hline Essential oils $^{\mathrm{a}}$ & \multicolumn{3}{l}{ Termite mortality $(\%)^{\mathrm{b}}$} \\
\cline { 2 - 4 } & $1 \mathrm{~d}$ & $5 \mathrm{~d}$ & $14 \mathrm{~d}$ \\
\hline $\mathrm{COH}$ & $5.3 \pm 2.3 \mathrm{~d}, \mathrm{e}, \mathrm{f}$ & $88.0 \pm 8.0 \mathrm{a}$ & $100.0 \pm 0.0 \mathrm{a}$ \\
COB & $2.7 \pm 1.2 \mathrm{f}$ & $40.0 \pm 4.0 \mathrm{~b}, \mathrm{c}$ & $100.0 \pm 0.0 \mathrm{a}$ \\
COL & $4.0 \pm 0.0 \mathrm{f}$ & $100.0 \pm 0.0 \mathrm{a}$ & $100.0 \pm 0.0 \mathrm{a}$ \\
CJH & $6.0 \pm 1.7 \mathrm{~d}, \mathrm{e}, \mathrm{f}$ & $100.0 \pm 0.0 \mathrm{a}$ & $100.0 \pm 0.0 \mathrm{a}$ \\
CJS & $4.7 \pm 5.0 \mathrm{e}, \mathrm{f}$ & $100.0 \pm 0.0 \mathrm{a}$ & $100.0 \pm 0.0 \mathrm{a}$ \\
CJB & $2.7 \pm 2.3 \mathrm{f}$ & $11.0 \pm 2.3 \mathrm{~d}, \mathrm{e}, \mathrm{f}$ & $41.3 \pm 1.2 \mathrm{~b}, \mathrm{c}$ \\
CJL & $24.0 \pm 5.3 \mathrm{c}, \mathrm{d}$ & $82.0 \pm 12.2 \mathrm{a}$ & $100.0 \pm 0.0 \mathrm{a}$ \\
CFH & $100.0 \pm 0.0 \mathrm{a}$ & $100.0 \pm 0.0 \mathrm{a}$ & $100.0 \pm 0.0 \mathrm{a}$ \\
CFS & $52.0 \pm 3.5 \mathrm{~b}, \mathrm{c}$ & $100.0 \pm 0.0 \mathrm{a}$ & $100.0 \pm 0.0 \mathrm{a}$ \\
CFB & $2.7 \pm 1.2 \mathrm{f}$ & $21.3 \pm 3.1 \mathrm{c}, \mathrm{d}, \mathrm{e}, \mathrm{f}$ & $55.3 \pm 5.0 \mathrm{~b}$ \\
CFL & $3.3 \pm 3.1 \mathrm{f}$ & $14.7 \pm 2.0 \mathrm{~d}, \mathrm{e}, \mathrm{f}$ & $26.7 \pm 4.6 \mathrm{c}, \mathrm{d}, \mathrm{e}$ \\
Control & $0.0 \pm 0.0 \mathrm{f}$ & $1.3 \pm 1.2 \mathrm{f}$ & $2.7 \pm 1.2 \mathrm{f}$ \\
\hline
\end{tabular}

Numbers followed by different letters (a-f) are significantly different at the level of $P<0.05$ according to the Scheffe test.

a CO: Chamaecyparis obtuse var. formosana, CJ: Cryptomeria japonica, $\mathrm{CF}$ : Calocedrus macrolepis var. formosana, $\mathrm{H}$ : heartwood, S: sapwood, B: bark, L: leaf.

b Means $(n=3)$ using 33 termites per replicate.

Table 2

$\mathrm{LC}_{50}$ values of 5 essential oils extracted from three coniferous trees against $C$. formosanus

\begin{tabular}{llll}
\hline Essential oils $^{\mathrm{a}}$ & \multicolumn{2}{l}{$\mathrm{LC}_{50}(\mathrm{mg} / \mathrm{g})$} & \\
\cline { 2 - 4 } & $1 \mathrm{~d}$ & $5 \mathrm{~d}$ & $7 \mathrm{~d}$ \\
\hline $\mathrm{COL}$ & $>10$ & 3.1 & 2.8 \\
$\mathrm{CJH}$ & $>10$ & 2.8 & 2.3 \\
$\mathrm{CJS}$ & $>10$ & 4.7 & 2.8 \\
$\mathrm{CFH}$ & 2.6 & 1.7 & 1.6 \\
$\mathrm{CFS}$ & 4.9 & 2.1 & 1.9 \\
\hline
\end{tabular}

a See Table 1.

Comparison with the $\mathrm{LC}_{50}$ values (Table 2) of the essential oils examined after 5 and $7 \mathrm{~d}$ of test against $C$. formosanus showed that C. macrolepis var. formosana heartwood essential oil $\left(\mathrm{LC}_{50}=1.7\right.$ and $\left.1.6 \mathrm{mg} / \mathrm{g}\right)$ exhibited the highest anti-termitic activity, followed by C. macrolepis var. formosana sapwood essential oil $\left(\mathrm{LC}_{50}=2.1\right.$ and $\left.1.9 \mathrm{mg} / \mathrm{g}\right), C$. japonica heartwood essential oil $\left(\mathrm{LC}_{50}=2.8\right.$ and $\left.2.3 \mathrm{mg} / \mathrm{g}\right)$, C. obtusa var. formosana leaf essential oil $\left(\mathrm{LC}_{50}=3.1\right.$ and $2.8 \mathrm{mg} / \mathrm{g}$ ) and then $C$. japonica sapwood essential oil
$\left(\mathrm{LC}_{50}=4.7\right.$ and $\left.2.8 \mathrm{mg} / \mathrm{g}\right)$. In addition, the $\mathrm{LC}_{50}$ values were $2.6,4.9,>10.0,>10.0$ and $>10.0 \mathrm{mg} / \mathrm{g}$ even after $1 \mathrm{~d}$ of test for C. macrolepis var. formosana heartwood and sapwood essential oils, $C$. japonica heartwood and sapwood essential oils and C. obtusa var. formosana leaf essential oil, respectively. These results demonstrated that both heartwood and sapwood essential oils of C. macrolepis var. formosana have excellent anti-termitic activities.

\subsection{Anti-termitic functions of C. macrolepis var. formosana heartwood and sapwood essential oils}

Fig. 1 shows the results obtained by applying $2.5 \mathrm{mg}$ of heartwood and sapwood essential oils of $C$. macrolepis var. formosana dissolved in $600 \mu \mathrm{l}$ of ethanol to $1 \mathrm{~g}$ filter paper samples. The heartwood essential oil displayed termiticidal activity not only in termite test $\mathrm{A}$, but also in termite test $\mathrm{B}$. The termite mortality of heartwood essential oil in termite tests A and B after $7 \mathrm{~d}$ was $100 \%$ and $95 \%$, respectively. In addition, the dead termites in termite test B were observed to be lying on the side of the filter paper impregnated with distilled water. Therefore, the anti-termitic functions of heartwood essential oil could be attributed to its toxicity and its repellent action. In addition, the sapwood essential oil displayed high activity in termite test $\mathrm{A}$, followed by termite test $\mathrm{C}$ and termite test $\mathrm{B}$ (termite mortality 62,46 and $13 \%$, respectively) after $7 \mathrm{~d}$. This suggested that the anti-termitic function of sapwood essential oil was due to its toxicity. The results demonstrated that both heartwood and sapwood essential oils of C. macrolepis var. formosana did not have respiratory poisoning functions for $C$. formosanus.

\section{Conclusions}

From the results it was concluded that heartwood and sapwood essential oils of C. macrolepis var. formosana and C. japonica and the leaf essential oil of C. obtusa var. formosana were termiticidal, showing $100 \%$ mortality after $5 \mathrm{~d}$ of test. The anti-termitic function of heartwood essential oil was due to its toxicity and its repellent action. Thus, the essential oil from C. macrolepis var. formosana heartwood could be used as a potential natural termiticide.
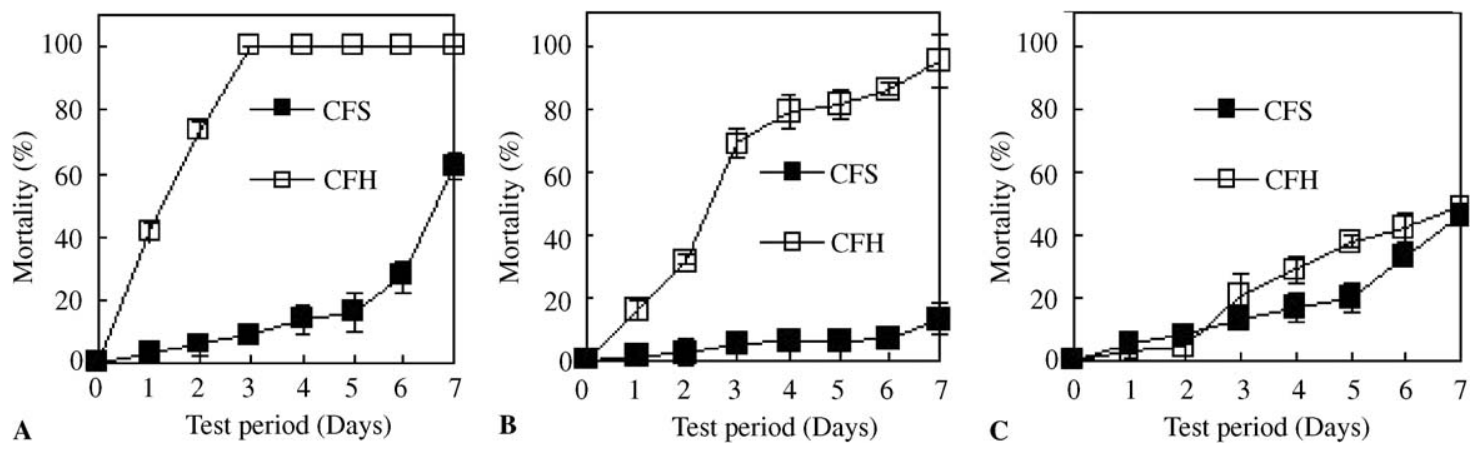

Fig. 1. Anti-termitic activities of essential oils extracted from C. macrolepis var. formosana heartwood (CFH) and sapwood (CFS) against C. formosanus at a dosage of $2.5 \mathrm{mg} / \mathrm{g}$ using three testing methods (A, B and C). 


\section{Acknowledgements}

We thank H.-Y. Lin (Experimental Forest of National Taiwan University) for supplying materials and Mr. ChienYung Hung and Mr. Wen-Ching Cheng (Jong Shing Pest Control Co. Ltd.) for providing the termites.

\section{References}

Arihara, S., Umeyama, A., Bando, S., Kobuke, S., Imoto, S., Ono, M., Yoshikawa, K., Amita, K., Hashimoto, S., 2004. Termiticidal constituents of the black-heartwood of Cryptomeria japonica. Mokuzai Gakkaishi $50,413-421$.

Bultman, J.D., Beal, R.H., Ampong, F.F.K., 1979. Natural resistance of some tropical African woods to Coptotermes formosanus Shiraki. For. Prod. J. 29, 46-51.

Chang, S.T., Wang, S.Y., Wu, C.L., Su, Y.C., Kuo, Y.H., 1999. Antifungal compounds in the ethyl acetate soluble fraction of the extractives of Taiwania (Taiwania cryptomerioides Hayata) heartwood. Holzforschung 53, 487-490.

Chang, S.T., Cheng, S.S., Wang, S.Y., 2001. Antitermitic activity of essential oils and components from Taiwania (Taiwania cryptomerioides). J. Chem. Ecol. 27, 717-724.
Chang, S.T., Cheng, S.S., 2002. Antitermitic activity of leaf essential oils and components from Cinnamomum osmophloeum. J. Agric. Food Chem. 50, 1389-1392.

Cheng, S.S., Wu, C.L., Chang, H.T., Kao, Y.T., Chang, S.T., 2004. Antitermitic and antifungal activity of essential oil of Calocedrus formosana leaf and its composition. J. Chem. Ecol. 30, 1957-1967.

Kang, H.Y., Matsushima, N., Sameshima, K., Takamura, N., 1990. Termite resistance tests of hardwoods of Kochi growth I. The strong termiticidal activity of kagonoki (Litsea coreana Léveillé). Mokuzai Gakkaishi 36, 78-84.

Ohtani, Y., Hazama, M., Sameshima, K., 1996. Crucial chemical factors of the termiticidal activity of hinoki wood (Chamaecyparis obtusa) II. Variations in termiticidal activities among five individual samples of hinoki wood. Mokuzai Gakkaishi 42, 1228-1233.

Park, I.K., Shin, S.C., 2005. Fumigant activity of plant essential oils and components from garlic (Allium sativum) and clove bud (Eugenia caryophyllata) oils against the Japanese termite (Reticulitermes speratus Kolbe). J. Agric. Food Chem. 53, 4388-4392.

Sakasegawa, M., Hori, K., Yatagi, M., 2003. Composition and antitermite activities of essential oils and Melaleuca species. J. Wood Sci. 49, 181-187.

Sogabe, A., Kinjo, K., Abe, F., Yamauchi, T., Yaga, S., 2000. Termiticidal substances from the heartwood of Cryptomeria japonica D.Don. Mokuzai Gakkaishi 46, 124-131.

$\mathrm{Su}$, N.Y., Scheffrahn, R.H., 1990. Economically important termites in the United States and their control. Sociobiology 17, 77-94. 